Article

\title{
Governance, Sustainability and Decision Making in Water and Sanitation Management Systems
}

\author{
Martín Alejandro Iribarnegaray ${ }^{1, *}$ and Lucas Seghezzo ${ }^{2}$
}

1 Research Institute on Non-Conventional Energy Sources (INENCO), National University of Salta (UNSa), National Agency for the Advancement of Science and Technology (ANPCyT), Avenida Bolivia 5150, A4408FVY, Salta, Argentina

2 National Council of Scientific and Technical Research (CONICET), INENCO-UNSa, Avenida Bolivia 5150, A4408FVY, Salta, Argentina; E-Mail: lucas.seghezzo@wur.nl

* Author to whom correspondence should be addressed; iribarnegarayma@gmail.com; Tel.: +54-387-4255516; Fax: +54-387-4255489.

Received: 14 September 2012; in revised form: 30 October 2012 / Accepted: 30 October 2012 / Published: 5 November 2012

\begin{abstract}
We explore the connections between the concepts of governance and sustainability and discuss their possible roles in water and sanitation management systems (WSMS). We see governance as a decision-making process that drives the relationship between social institutions and the public affairs of a given society. We understand sustainability as a combination of spatial, temporal, and personal aspects, and we argue that this definition is more comprehensive than the traditional triple bottom line of economy, environment, and society. We combined these two concepts into a new conceptual framework of "governance for sustainability" that is theoretically sound and arguably appropriate to understand local WSMS. To illustrate this framework, we developed and estimated a Sustainable Water Governance Index (SWGI) for the city of Salta, Argentina. This aggregated index was calculated with data from literature, information from the city's water company and other local institutions, field visits, and interviews. The SWGI for Salta obtained an overall score of 49 on a $0-100$ scale, which fell into the "danger" range. We discuss the advantages and limitations of the method and conclude that aggregated indices such as the SWGI, complemented with contextual information, can be a helpful decision-making tool to promote more sustainable WSMS.
\end{abstract}

Keywords: decision making; governance; sustainability; water and sanitation 


\section{Introduction}

The complexity and close interconnections between social and environmental issues need to be explicitly acknowledged in the management of water and other natural resources. In these social-ecological systems (SESs), attention to political, cultural, institutional, historical, and personal issues (such as human rights) is increasingly important [1,2]. In the specific case of water management, purely technical approaches seem insufficient to adequately respond to the demands of a constantly growing population and mounting water consumption pressure [3,4]. In those cases, the relationship between the concepts of governance and sustainability, and their possible roles for the improvement of decision-making processes in water and sanitation management systems (WSMS) is receiving increasing attention [5]. In fact, several "water crises" around the world appear more related to management failures than to physical resource scarcity [6,7]. It is encouraging that some good practices have emerged from recent water and sanitation projects, but there is still much to be done to ensure the sustainability of WSMS, not least complying universally with the United Nations' Millennium Development Goals (MDGs), which pledge to reduce by half the proportion of people without sustainable access to safe drinking water and basic sanitation by 2015 [8].

In this paper, we combine two particular notions of governance and sustainability into a new conceptual framework we believe is theoretically comprehensible and potentially useful for describing and understanding the governance of WSMS and, eventually, for improving their sustainability. Based on the new conceptual framework, we developed the Sustainable Water Governance Index (SWGI). To illustrate this concept, we used the SWGI to assess the governance and sustainability of the WSMS of the city of Salta, in northern Argentina. We discuss the potential usefulness of the SWGI in fostering sustainable decision-making processes in the region.

\section{Governance and Sustainability}

\subsection{Governance}

The term "governance" has been extensively used in the last decades in academic and policy circles, but it has very different and even contradictory meanings. In generic terms, governance refers to the processes of decision-making by which society defines and handles its problems [9,10]. The role of governments is clearly essential in most governance processes, but governance must be distinguished from "government" as a centralized management of authority and also from "governing" as a purposeful effort to control or manage society [11]. Particularly influential has been the World Bank's notion of governance as "the set of traditions and institutions by which authority in a country is exercised" ([12], p. 2). "Good" governance, as understood by the World Bank, generally implies, among other things, that states are supposed to minimize their size and promote economic and financial stability, assuming that this is a way to deal with social inequalities and poverty [13]. This concept of good governance loaded with neoliberal connotations did not work as expected in many developing countries, leading instead to more concentration of power in a few economic and political actors, and to a drastic reduction in the control capacity of state agencies [14]. Contemporary ideas of governance draw attention to the values, norms, and principles that underpin decision making and, by doing so, they highlight the central role of individuals and their personal 
attitudes and behaviors at the origin of governance processes $[15,16]$. Building on democratic theory and embracing political pluralism, contemporary theories of governance also emphasize the multiscale sociopolitical perspectives as the basis of the interaction between different types of actors interested in solving societal problems [17]. Given that human relationships are not without conflicts, governance must also take into account the existence of conflicting visions [18]. As a result, good governance might not necessarily lead to management efficiency understood only in economic terms.

The governance of SESs must cope with high levels of complexity and uncertainty, as well as with the dynamic character of multistakeholder decision-making processes. Particularly inclusive in this regard are the concept of "interactive governance" [19] and the so-called "governance analytical framework" (GAF) [20]. Interactive governance has been defined as "the whole of interactions instigated to solve societal problems and to create societal opportunities, including the formulation and application of principles guiding those interactions and care for institutions that enable or control them" ([19], p. 820). The interactions and power relationships between institutional and individual actors are at the center of the idea of interactive governance, and so are the dynamic processes by which choices are made. The GAF, in turn, sees governance as a social fact deserving study, and defines it as "the formal and informal collective processes that determine how decisions are made and how social norms and institutions are elaborated in relation to the public affairs of a given society" ([21], p. 10). The GAF can be summarized as the interplay between five analytical categories: problems, actors, nodal points (or interaction spaces), norms, and processes (see a schematic diagram in Figure 1, left). More details about the definition of these categories can be found in Hufty [21]. Remarkable resemblances can be seen between interactive governance and the idea of governance undergirding the GAF. Like interactive governance, the GAF puts emphasis on decision-making processes as cause and consequence of the generation of social norms intended to solve problems, create opportunities, and facilitate human relationships. The GAF has been developed after experiences of environmental governance in Latin America and, consequently, holds great potential to understand and explain governance processes in this region.

Power relationships are also paramount to the GAF, although power struggles between different stakeholders over a specific issue such as water and sanitation management are not always equally relevant. Several definitions and typologies of power can be found in the literature [22]. For governance purposes, all types of power (coercive, utilitarian, and normative, as defined in [23]) might be relevant at some point or in specific places. "Normative" or "social" power seems especially pertinent, in particular when the symbolic attributes of that type of power relate to (the generation of) formal or informal norms conducive to building a virtuous (or vicious) circle towards more sustainable (or unsustainable) management systems. "Power" is just one of the attributes necessary to identify relevant actors in multistakeholder processes, but "legitimacy" or "urgency," among other criteria, can be equally important [22]. Therefore, while acknowledging the central importance of power, more sustainable decision-making processes must always take into account those actors without power but with enough legitimacy, urgency, or rights to claim justice with respect to a particular issue. According to the GAF, careful analysis of the historic, social, and political context is also important in identifying actors, powerful or otherwise, and describing the specific types of governance practices taking place in a particular location. To explore some of the power struggles generated at the interface between social and environmental issues, and scrutinize the ideas and discourses supported by 
different actors when confronted with a given policy decision, the GAF resorts to methodological approaches such as political ecology [24-26].

\subsection{Is the Notion of Sustainable Development a Suitable Companion to Governance?}

The idea of "governance for sustainable development" assumes that the traditional structures of governance can be adjusted in order to "ensure that social development proceeds along a sustainable trajectory" ([27], p. 5). Since the World Commission on Environment and Development (WCED) issued the "Brundtland report" [28], sustainable development is usually presented as a quest to balance economic, social, and environmental aspects. This idea of sustainable development has been contested on ideological and practical grounds [29,30]. We have discussed elsewhere several criticisms of the concept of sustainable development [31]. In the ideological arena, it has been noted that the WCED definition, in the wake of neoclassical economic thinking, still presupposes a direct connection between economic growth and issues of poverty alleviation and income distribution. Yet a direct link between purely economic growth and equity is not obvious, especially in developing countries. In fact, redistribution and equity are to a great extent contradictory with the key, neoclassical objective of economic activity as maximization of short-term "economic efficiency" (general improvement of the overall economic situation irrespective of the initial distribution of wealth), and an increase in national income measured through rough indicators such as the Gross Domestic Product (GDP) (assuming that it is directly proportional to the well-being of society) [32-34]. On a more pragmatic front, the existence of the so-called "decoupling" between the use of natural resources and economic growth in market economies, often utilized as irrefutable evidence of progress towards sustainable development [35], has been put under scrutiny. Many examples of decoupling have been based on dubious indicators and are very confined in space and time, remaining merely rhetorical even in developed countries [36]. These two criticisms alone cast doubt on the efficiency of economic instruments and market mechanisms for an equitable allocation of resources. More importantly for the sake of this paper, they also question the usefulness of the traditional idea of sustainable development to support an innovative approach that can foster governance for real "sustainability," instead of governance for (the contested notion of) "sustainable development" [37-39].

The original definition of sustainable development has been expanded to explicitly include other aspects, such as institutions, as a way to acknowledge the need to reform societal organizations in order to maximize opportunities for sustainable development [27,40]. However, this new approach adds little to the traditional idea of sustainable development and can be subject to the same criticisms. Basically, it continues to underestimate the importance of cultural diversity and other place-based issues; it continues to embrace neoclassical economic ideology which, by definition, pays predominant attention to short-term issues; and it continues to underestimate the role of citizens and individual persons as the ultimate protagonists of change, subsumed into a Eurocentric idea of a strongly institutionalized society in which relatively few basic needs remain unsatisfied. To circumvent the shortcomings of the conventional idea of sustainable development, a "five-dimensional" sustainability definition has been proposed. Five-dimensional sustainability is a conceptual platform within which the spatial, temporal, and personal aspects of development can be openly discussed and 
harmonized [31]. This idea was represented with a new sustainability triangle formed by "Place," "Permanence," and "Persons" (the new 3Ps) (Figure 1, right).

Figure 1. Left: the Governance Analytical Framework (GAF) (adapted from [21]). Right: the five dimensions of sustainability (from [31]).
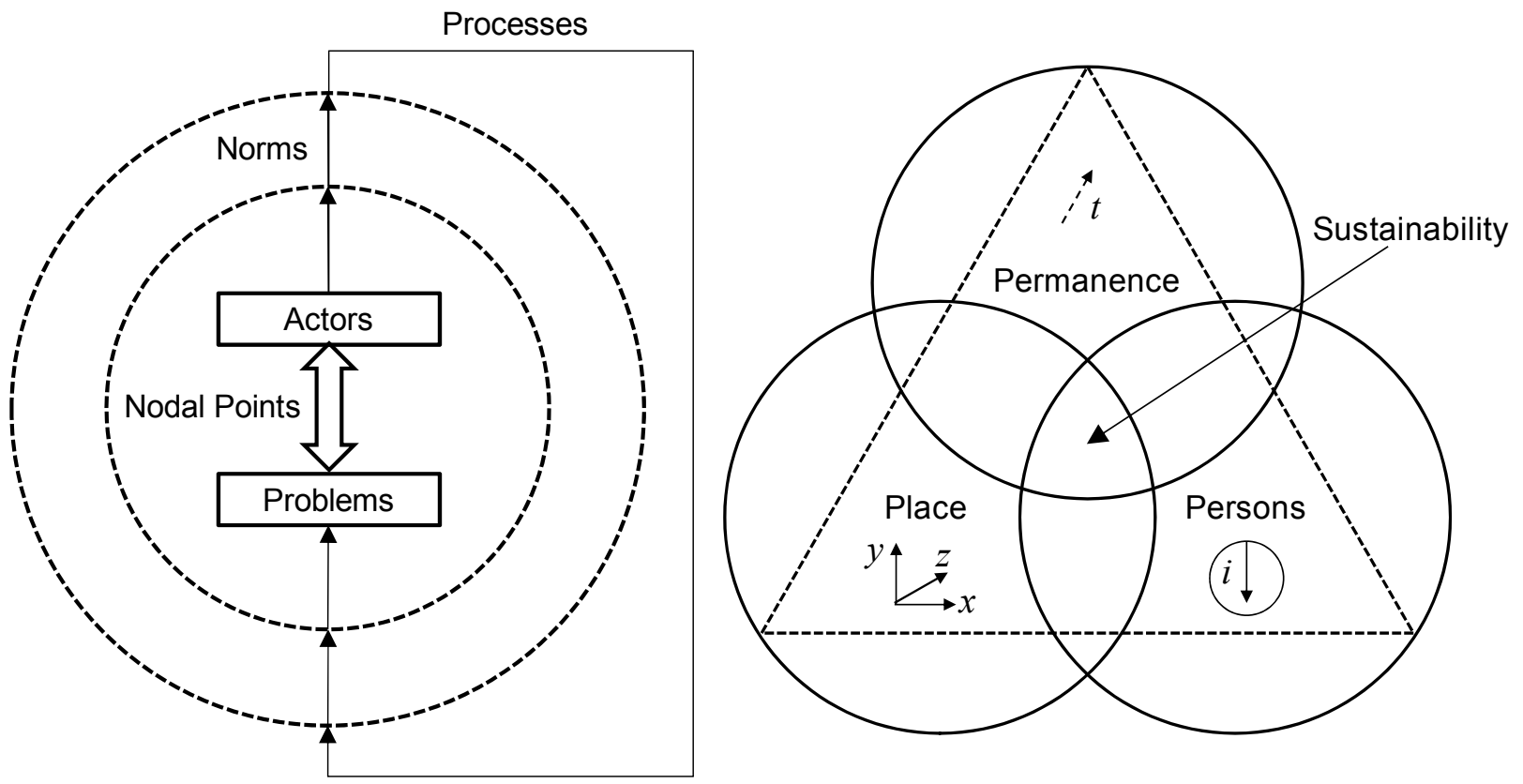

Place contains the three dimensions of space $(x, y$, and $z)$ and should be a reliable depiction of current circumstances on the ground (the specific "system" under analysis, but also its context). It includes most economic, social, and environmental issues as usually understood today. Place-based analyses are critical to sustainability because they are the only way to acknowledge the importance of local characteristics such as power relationships and history, often hidden by the increasing centrality of a globalized economy [41-42]. The geographical and cultural "place" is where intra-generational justice can be pursued. Permanence is the fourth dimension of time $(t)$, necessary to contain the medium- and long-term issues associated with intergenerational justice, and deal with the future environmental consequences of present actions, as indicated by Barbara Adam for nuclear waste disposal, among other issues [43]. These issues are overlooked in neoclassical economic thinking that is strongly biased in favor of the present generation [33]. Individuals and society play different roles in the pursuit of sustainability since we are not an undifferentiated society facing an equally undifferentiated nature [15]. Therefore, Persons, the fifth and human dimension $(i)$, is indispensable for dealing with issues of identity, human rights, sense of belonging, and personal happiness [44-46]. This new approach to sustainability is loaded with political meaning because it is open to place-bound analysis, historical perspectives, gender issues, empowerment, and other rights-based approaches. 


\subsection{Governance for Sustainability}

A combination of the concept of governance, as understood in the GAF, and the five-dimensional sustainability notion might help establish an intrinsically political theory of social change with unambiguous participatory and normative significance. In Figure 2, related categories of these two concepts have been merged or combined to represent a new conceptual framework of "governance for sustainability." This concept is not entirely new (see [27,39]) but, for our specific case, we defined it in extenso as "an interactive and adaptive decision-making process by which individual citizens, institutions, and other societal actors, openly and democratically discuss their situation, problems, and ideas, and influence the long-term evolution of society by generating and managing plans and strategies intended to ensure the equitable distribution of resources, respect human rights and cultural diversity, and protect nature."

Figure 2. Schematic diagram of the idea of governance for sustainability. Dotted lines indicate permeable boundaries open for interactions. More details in the text.

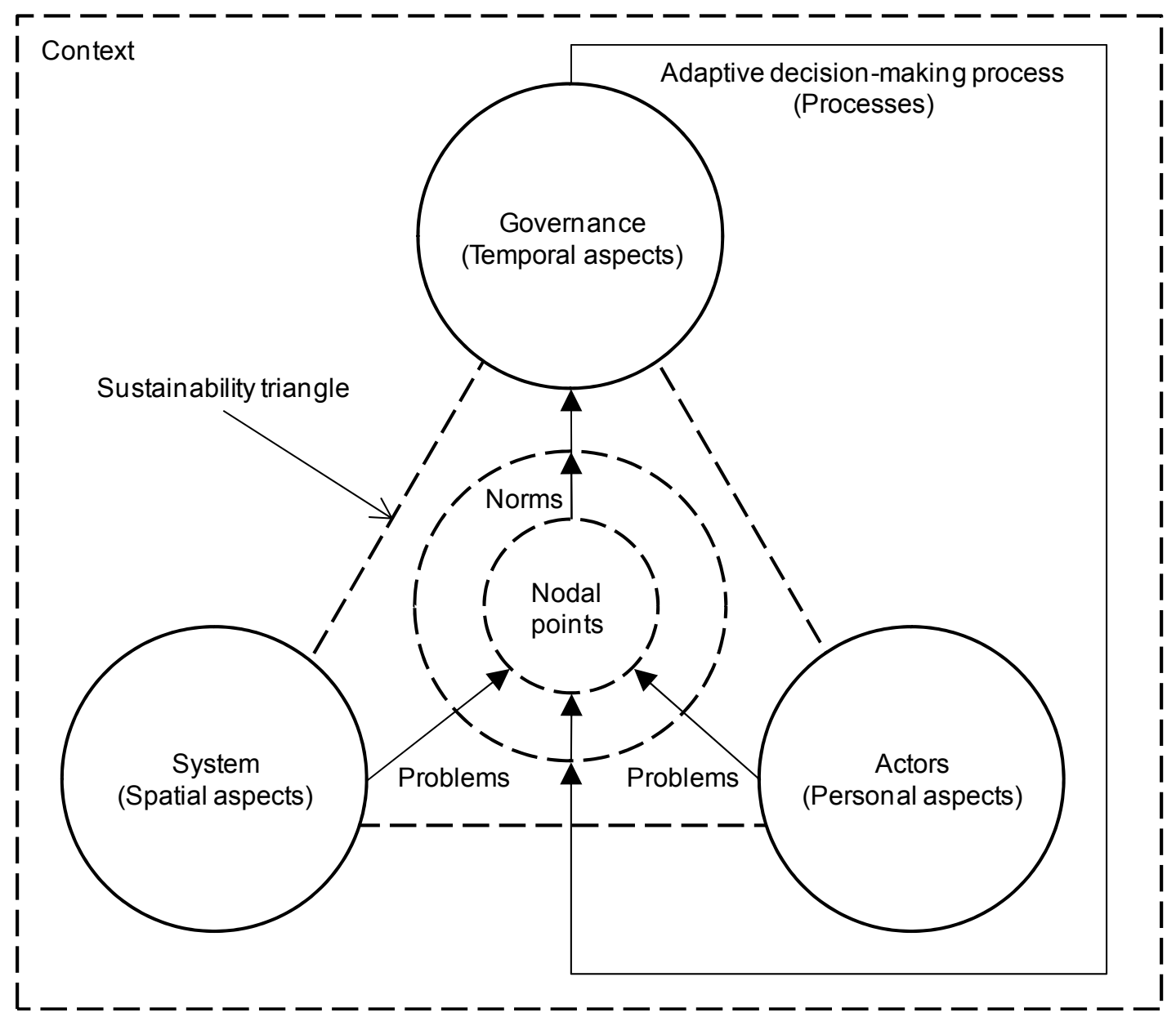

Our three sustainability categories (or aspects) are indicated between brackets within the full circles in Figure 2. Clear associations can be established between these aspects and the elements of the adopted idea of governance. The framework depicted in Figure 2 also builds on the general framework for analyzing sustainability of SESs developed by Elinor Ostrom and coworkers $[1,2]$. With some 
minor adaptations, the core subsystems of that framework can be related to the categories in our conceptual scheme.

Problems are originated mostly in local systems (System corner) and constitute direct causal links to the generation of interaction processes. These problems can only be detected and formulated after a grounded analysis. Spatial aspects analyzed in the framework of the local (and global) cultural and environmental context, are therefore the main source of problems and issues for the entire process of governance. The Actors corner can also be a starting place for additional "problems," as long as the perception of sustainability-related issues depends to a great extent on personal perspectives and subjective constructions. Problems and actors converge in nodal points, the quintessential physical and/or virtual location of the process of governance for sustainability. Interactions in nodal points, within the framework of existing social norms (formal or otherwise) generate an iterative and adaptive process of decision making. Given the right conditions, the outcomes of this process can lead the system to a more sustainable situation. Institutions, understood not only as administrative structures, but also as the values, worldviews, and attitudes of the actors and individual persons acting therein, play a central role all along this decision-making process [47]. These institutions, and more specifically their planning and management capacity (in other words, their capacity to facilitate governance processes), are central tenets of the temporal sustainability of any system. An assessment of the suitability of local institutions can thus be regarded as a semiquantitative proxy of governance for sustainability (Governance corner).

Interactive processes are not only discursive or organizational; they are also loaded with practical consequences since decision making is often one of their main outcomes. When the objective of this deliberation is increasing the long-term sustainability of a given society or part of it, decision making is often linked to an explicit or tacit planning process that generally takes place in, or gives shape to, local institutions. Planning for sustainability is, almost by definition, linked to the essentially normative idea of sustainability adopted by this particular society for this particular combination of space and time [48]. Therefore, the adequacy of the governance system to promote more sustainable outcomes could, in principle, be estimated through an assessment of the local planning capacity. This way of looking at governance as having an essentially prescriptive aspect differs from previous ideas that assume that governance is a nonnormative and nonprescriptive concept [21].

Personal and collective political action can be exerted through participation inside institutions, which are not always (and not necessarily) physical organizations or written norms. Informal interaction mechanisms and customary habits can also be considered institutions and can therefore take part in governance processes. From a practical point of view, institutions are social entities intended primarily to solve specific problems (especially in places where basic problems abound such as in developing countries). Thus "problems" (or rather "problem solving") can be seen as a central justification for the existence of many institutions and social norms, becoming in that way the main "objects" of governance [17,21]. However, a note of caution should be introduced here about the nature and definition of problems. In generic terms, problems are specific issues that need solving (such as water catchment, treatment and distribution), and usually require cooperation and concerted action. However, there might be other reasons for cooperating (such as pleasure, entertainment, bonding, the sharing of personal feelings, etc.) that should not be excluded from governance processes, even if they do not have a direct or obvious link to the solution of a given problem [49]. 
Therefore, bilateral or multilateral citizen networking and social interactions in nodal points (and even outside them) do not only or do not always contemplate problem-solving and opportunity-creation activities, but also include the open discussion of ideas and other communitarian actions that facilitate human relationships and promote social cohesion. These activities, which can be considered ends in themselves for democratic theory, are also key in democratic decision-making practices, especially when grounded in particular public spaces [50,51].

Public participation has been seen as both a prerequisite and an element of governance for the sustainable management of natural resources [52]. The ultimate meaning of "participation," however, is a central issue of debate among different actors struggling to set the political agenda. State institutions often approach participation as an invitation to stakeholders to be informed on policy programs and actions. This type of participation is very low in the so-called "participation ladder" proposed long ago [53] and can overrule or ignore the rights of social and cultural minorities over issues such as water management [18]. Participation in its broadest sense requires identification of all relevant stakeholders, a more direct link between grassroots practices and institutionalized decision making, and a public debate conducive to some kind of social learning [54]. The optimum degree of public participation is highly dependent on local characteristics. In the provision of services such as drinking water, for instance, considerations of human rights oblige states to ensure a basic service quality irrespective of the degree of public participation [55]. Even in these cases, public participation can be relevant as, for instance, citizen control over the performance of water utilities (through users associations, trade unions, regulatory bodies, etc.). Unrestricted access to relevant system information is therefore a basic precondition for this or any type of participation to be possible and constructive $[39,40,56]$. Institutions can also function as nodal points. In fact, most nodal points are usually set up by or within institutions. However, the individual persons representing or belonging to institutions can themselves be actors in the process of governance for sustainability. These and other possible circumstances can render management systems very complex and, for that reason, any general conceptual scheme such as the one we propose in Figure 2 should be used or extrapolated with caution.

Even though one of the core governance activities is problem solving and opportunity creation, there is little in contemporary definitions of governance that indicates precisely what these problems are or how they should be solved in particular situations. This has probably been an overreaction to the extremely normative, unashamedly neoliberal, and arguably authoritarian idea of governance promoted by the World Bank in past decades. However, without a normative, also admittedly ideological complement, the idea of governance remains mostly analytical, interested more in the positive description and assessment of organizational means and styles than in the visualization and proposition of desirable futures. It might have plenty of explanatory power and can be useful for cultural and anthropological studies but, as discussed in [57], disregard of normative and political aspects is particularly worrisome because it reduces the potential for social innovation, let alone radical change. Moreover, without the complement of a contextual perspective and a more prescriptive vision of a desirable future, current ideas of governance risk becoming politically neutral and therefore theoretically serviceable to different ideologies and philosophical standpoints that could even fall outside of democratic discourses.

The notion of sustainability we adopted in this paper has normative undertones and is concerned with means (such as genuine participation and respect for human rights), but also with ends (such as 
taking action to build a more sustainable future). It gives renewed relevance to planning and decision making as indispensable tools to work "for" sustainability. The idea of sustainability, as understood in this paper, can be useful to point governance to a desirable direction, no matter how blurred or even admittedly unachievable the final destination could be. In that sense, we understand governance as a vehicle and sustainability as the road map. We believe that "governance for sustainable development" and "governance for sustainability" cannot be used as synonyms because the criticisms raised against the idea of sustainable development could also be raised against the idea of governance for sustainable development. On a more semantic note, we prefer the term "governance for sustainability" over "sustainability governance" because it better conveys the idea that the search for sustainability is a dynamic, continuous transition process, and that ultimate sustainability will probably never be reached. Whether the concept of governance contains or is contained by the idea of sustainability is subject to debate. Whatever the case might be, we believe that the combined idea of governance for sustainability is an interesting conceptual and political framework that can help understand and facilitate processes of transition to a more sustainable society. The idea of governance for sustainability, though fraught with theoretical and practical difficulties, is arguably appealing to both scientists and policy makers as an analytical and normative conceptual framework. It is our contention that the idea of governance for sustainability can contribute to the generation of societal changes based on more deliberative, ethics- and rights-based practices. Some of these practices could gradually complement and, in some cases, even replace markets or states as the main drivers and facilitators, respectively, for decision making $[37,39,56]$.

\section{Case Study: Water and Sanitation Management in Salta, Argentina}

To test and illustrate the idea of governance for sustainability, we took as a case study the WSMS of the city of Salta, in northern Argentina. We assessed this system with a semiquantitative aggregated index composed of a set of sustainability indicators founded in explicit theoretical and ideological assumptions. We do not see this index as a definitive measure of the sustainability of the system, but rather as a potentially useful first step in developing such sustainability indicators. We also believe that the use of this or similar assessment tools can help clarify what is important in the system, establish measurable policy objectives, and communicate progress to policy makers and the public [58-62].

\subsection{System Description}

The city of Salta has a population of more than 500,000 [63]. About $65 \%$ of the drinking water consumed in Salta is extracted from more than 150 wells distributed around the city. The remaining water comes from surface sources and is captured either directly from rivers or indirectly through shallow drains located close to waterways. This water is later conveyed to the city by means of closed aqueducts. According to information provided by the water company, water availability per capita is more than 600 liters per day, which should be more than enough to meet the city's needs. Sewage is collected through a sewerage network designed as separate from urban runoff, although illegal connections between these two systems are common. Collected sewage is conveyed and treated in two aerobic wastewater treatment plants and final effluents are discharged into rivers. 
Drinking water and sanitation services in Salta, formerly provided by state agencies, were privatized in 1998. The entire provincial territory (more than $150,000 \mathrm{~km}^{2}$ ) was given in concession to one company. After more than 10 years in private hands, services reverted back to a mostly state-owned company. The government held in reserve the right to reprivatize the new company [64]. Low investments and failure to provide services to the poorest areas of the city were a constant during both the public and private periods, as was also reported in other parts of the country and the world $[65,66]$.

Despite changes in the type of management, the system's governance has always been markedly centralized and hierarchical [19], with decision making and planning clearly influenced by short-term economic criteria and political circumstances. The dominant actor throughout was the water company itself, able to determine rules, relationships, and management procedures [21,22]. This dominant power position counted with government endorsement even during the privatization process. The company's interaction with end-users and other actors was (and still is) mostly limited to responding complaints about household service problems or water and sewage leakages. Besides the water company, other institutions are linked to the WSMS of the city, such as the governmental regulatory agency (ENRESP_Ente Regulador de los Servicios Públicos), the provincial Secretary of Water Resources (SRH-Secretaría de Recursos Hídricos), and the Municipality of Salta (Municipalidad de Salta). These institutions have different, but sometimes overlapping, competencies for managing water resources. Being also a state agency, the role of ENRESP has somewhat weakened since the water company is again in state hands. To date, there are no organized associations of water users in the city. Norms and regulations are not homogeneous throughout the entire provincial territory, mainly with respect to wastewater discharge standards, and some municipalities (in particular the Municipality of Salta), have more detailed and stricter standards than others.

\subsection{The Sustainable Water Governance Index (SWGI)}

For a number of years we have been working on an integrated sustainability index that could be applied under local circumstances to assess WSMS. That effort led to the development of the Water and Sanitation Sustainability Index (WASSI), which has been described at length elsewhere [67]. Suffice it to say here that the WASSI was built on the five-dimensional sustainability concept and it was therefore divided into three generic subindices: Place, Permanence, and Persons. The "Place" subindex evaluates the relationship of the management system with its environment and the biophysical and cultural territory upon which it operates. Indicators within this subindex point to environmental aspects of the WSMS such as water availability, water quality, changes in aquifer levels, water wastage, and water pollution, among others. Subindex "Permanence" assesses short, medium, and long-term aspects of the WSMS, with indicators that reflect the local capacity to solve problems, improve the management system, and ensure the coverage of basic human needs. This subindex is mostly focused on planning ability and institutional aspects. The "Persons" subindex of the WASSI puts additional emphasis on the personal aspects of the management system, with indicators that highlight the human dimension of water management in times of scarcity and unequal access to water and sanitation services.

Building on our experience with the WASSI, we developed a complementary index called the Sustainable Water Governance Index (SWGI) for the city of Salta. As postulated above, the 
governance aspects of the WSMS belong mostly in the temporal pillar of our conceptual framework of sustainability. Therefore, the SWGI can be seen as an expansion of the Permanence subindex of the WASSI. For that reason, some essentially environmental issues already included in the WASSI have been deliberately left out of the SWGI. Our idea of sustainability has multiple levels, and it can be understood as nested tiers of variables that interactively affect how other variables help or do not help to explain outcomes. Each tier can, to a certain extent, be explained in spatial, temporal and personal terms. Therefore, within the temporal corner of the WASSI it is also possible to identify distinctively spatial, temporal, and personal second-, third-, and even fourth-tier variables, and to analyze at a deeper level all the elements of our governance for sustainability conceptual framework. Conversely, when information to estimate low-level variables is insufficient or unavailable, aggregated values can be used as estimations of first- or second-tier categories (see [1], p. 15186). By putting actual figures to the idea of governance for sustainability in a specific case study, we expect to improve our understanding of the WSMS under analysis, facilitate societal discussions, and assess progress towards sustainability.

Information needed to build the SWGI was collected by several means including literature retrieval (including local media), field visits, and semistructured interviews conducted with officials of the institutions related to water management between 2009 and 2011. The index contains quantitative objective measurements, and semiquantitative figures. The latter are numerical estimations reflecting subjective, expert and nonexpert judgments obtained by means of personal consultations, perception surveys, panels of relevant stakeholders, and other participatory techniques [68]. The selection of indicators and variables was guided not only by their ability to reflect a relevant aspect of the system but also by their amenability to numerical translation [62]. Both objective measurements and subjective value judgments were converted to a normalized 0-100 scale using transformation functions. The extremes of the normalized scale ( 0 and 100) were linked to specific "anchor points," namely those points in the original scale considered the worst and best attainable (or tolerable) values, respectively, of the variable under assessment in terms of governance for sustainability [69]. When indicators are inherently subjective/judgmental, expert and nonexpert assessment teams face the difficult task of assigning numerical values to those indicators and selecting transformation functions according to their particular idea of (local) sustainability. The validity of these values will be somewhat related to the validity and social acceptability of the stakeholders in the assessment team. The selection of criteria, thresholds and transformation functions "is a specifically political choice, conditioned by the purpose of the investigation and the categories of concern of the researcher" ([26], p. 91). The range of possibilities is endless, and this is why the participation of local stakeholders is paramount in the assessment process.

For the variables used in this study, and especially in the range considered in the transformation functions, linear relationships between the selected variables and the normalized scale were assumed to be the best choice in terms of simplicity, and for evaluation and communication purposes. The values obtained were rounded to integer numbers and judged against the following governance for sustainability ranges: 0 to $24=$ Unacceptable (red), 25 to $49=$ Danger (yellow), 50 to $74=$ Good (green), 75 to $100=$ Excellent (blue). For the purpose of this work, the acceptability threshold was set at 50 . This value can be changed at will by the assessment team and can become part of the planning and improvement strategy. Defining a threshold is important to determine the magnitude of the 
measures required. However, fixing a threshold might not be necessary if the study is merely descriptive. For planning purposes, it could be interesting to fix several thresholds that might define different planning scenarios. In fact, the lower ends of each range (red, yellow, green, blue) could be seen as different thresholds or milestones. The determination of thresholds for a governance analysis strongly relates to the will of the body politic in question. Thresholds and transformation functions are certainly a political and managerial tool and, as such, they are also prone to adjustments by decision makers or assessment teams. Adjustments can be based on new information, financial limitations, shifting objectives, and many other reasons, yet always with the fundamental goal of continuously improving the sustainability of a given system under local constraints, according to a locally agreed upon vision of a desirable future. This is intrinsically political and place-based (or "situated"). Scientists have a lot to say in this debate, as they can provide information and concepts that might help the decision-making process. However, science cannot claim for itself a monopoly on the truth nor question situated knowledge from a positivist, allegedly universal standpoint.

Measures and actions must be recommended according to the value obtained for the entire SWGI, or for specific components. Relief and restorative measures need to be implemented if a certain category falls in the lowest quarter, corrective actions in the second quarter, optimization in the quarter above the threshold, and monitoring and maintenance in the top quarter. The primary objective of numerical transformations was to classify our system according to the broad ranges stipulated above and, ultimately, to identify areas that require corrective action. Yet we can also make use of even minor numerical differences between indicators in order to prioritize actions and establish a gradual and rational improvement plan.

As it can be seen in Table 1, the SWGI has three main assessment categories or tiers: aspects, descriptors, and indicators. Whenever possible, each category was estimated by defining three subcategories: three aspects for the entire index, three descriptors per aspect, and three indicators per descriptor (in turn, each indicator was defined by one or more fourth-tier variables). It is our contention that in the same way as the concept of governance embodies mainly the temporal aspects of the sustainability of the entire water system, the three aspects of the SWGI, namely Access, Planning, and Participation represent respectively the spatial, temporal, and personal aspects of our idea of governance for sustainability. It is also possible to select three descriptors within each aspect and three indicators within each descriptor as to represent the spatial, temporal, and personal facets of that respective category. This method generates multilevel "sustainability triangles," each of which reproduces the idea of sustainability at a deeper level. In this way, it is more likely that the assessment be conceptually coherent irrespective of the scale or the level of detail at which we work.

Descriptors are those characteristics or general attributes of a given system, or part of it, that are essential for the assessment of its sustainability (like physical health is essential to assess one's wellbeing) [70]. Indicators are the measurable variables or parameters that give numerical or qualitative value to the performance of descriptors (like body temperature is useful to assess one's health) [71-73]. Indicators must be simple, relevant, and as sensitive as possible to detect changes and trends.

Descriptors selected for the aspect Access intend to describe the most important components of the human right to water, namely economic accessibility (Costs), free access to enough information on the system (Information) [71], and a basic water allowance sufficient to cover basic 
needs (Needs) [74-76]. These descriptors are essential to understand the current situation in the city and were considered as proxies for the spatial aspects of the system's governance for sustainability, namely those linked with problem-solving and compliance with the principle of intra-generational justice. Indicators were selected to identify different types of problems by means of a place-based analysis. As indicated above, strictly environmental issues (water quantity, water quality, water pollution, etc.), paramount in sustainability assessments, have been taken into account in our previous analysis of the sustainability of the entire water system (the WASSI) and, for that reason have not been included in the SWGI.

Aspect Planning contains three descriptors that assess local institutional capacity. We decided to concentrate on institutions to characterize this aspect assuming a direct link between institutions, particularly their planning capabilities under local circumstances, and their possibility to promote governance for sustainability [47]. Within this aspect, each descriptor (Resources, Projects, Personnel) was based on three aggregated indicators, as described in Table 1. This institutional assessment involved an evaluation of different aspects of local institutions organized in nine indicators (detailed results were presented elsewhere [77]). The existence of resourceful, proactive, and professional institutions can be considered as a prerequisite for medium- and long-term planning processes. Therefore, institutional capacity reveals temporal attributes that can help ensure the effective compliance of the right to water in a framework of intergenerational justice. Descriptors and indicators for this aspect consider, among other things, the characteristics of the regulation process (clearly related to norms), the degree of public participation in the formulation of water projects (in specific, nodal points), and the level of professional training within water-related institutions (an appraisal of the type of actors involved).

In the case of the Participation aspect, we faced the difficult task of assigning numerical estimations to the inherently personal descriptors selected (Attitudes, Worldviews, Values). This problem was exacerbated by the lack of previous research on existing social perspectives and ideas with respect to the water and sanitation system. To overcome these difficulties, we assumed that recognizable behaviors such as convening and/or participating in public audiences and other meetings could be seen as a composite, emergent estimation of those descriptors. For that reason, we defined a new, combined descriptor and named it "Interactions." This descriptor points distinctively to the merged concept of governance for sustainability by looking at the existence of spaces for interaction among different actors. This descriptor was assessed using the number of participatory events (public Audiences) organized per year by the water company in order to inform and consult the public about water-related projects and investments. Public Audiences of this type can be motivating interaction spaces for users as well as other actors to exercise their civic rights and participate in water-related decision-making processes. The number of actual events reflects both the company's decision-making policy and the willingness of specific-individual or institutionalized actors to participate in water governance. We believe that participation in these events indicates the degree of personal involvement in water and sanitation issues. This indicator therefore encapsulates the personal aspects of the management system, from the most intrinsically personal values to the temporal worldviews articulated by different actors as a basis for the construction of personal attitudes and collective action in the field. A discussion on the theoretical, practical, and ethical implications of quantifying or estimating values, worldviews or attitudes exceeds the scope of this paper. Suffice it here to say that, if necessary, semiquantitative 
estimations of these descriptors could be obtained with existing survey techniques such as Q methodology, a method developed to analyze societal subjective value priorities with respect to specific environmental or social issues such as water management $[78,79]$.

Table 1. Categories used to build the Sustainable Water Governance Index (SWGI) for the city of Salta, Argentina.

\begin{tabular}{|c|c|c|c|c|}
\hline \multicolumn{2}{|l|}{ Aspect } & \multicolumn{3}{|l|}{ Descriptor } \\
\hline Name & Definition & Name & & $\begin{array}{l}\text { Description/Indicators used in the } \\
\text { assessment }\end{array}$ \\
\hline \multirow{3}{*}{$\begin{array}{l}\text { Access } \\
\text { (Spatial } \\
\text { aspects) }\end{array}$} & \multirow{3}{*}{$\begin{array}{l}\text { Compliance of the } \\
\text { right to water } \\
\text { including physical, } \\
\text { economic and } \\
\text { social availability }\end{array}$} & Costs & & $\begin{array}{l}\text { Economic accessibility to water and sanitation } \\
\text { services }\end{array}$ \\
\hline & & \multicolumn{2}{|l|}{ Information } & $\begin{array}{l}\text { Quantity and quality of freely accessible } \\
\text { information concerning the water and sanitation } \\
\text { system }\end{array}$ \\
\hline & & \multicolumn{2}{|l|}{ Needs } & $\begin{array}{l}\text { Indicates whether everybody has access to the } \\
\text { minimum amount of water needed to cover basic } \\
\text { needs }\end{array}$ \\
\hline \multirow{3}{*}{$\begin{array}{l}\text { Planning } \\
\text { (Temporal } \\
\text { aspects) }\end{array}$} & \multirow{3}{*}{$\begin{array}{l}\text { Management } \\
\text { capacity and } \\
\text { suitability of local } \\
\text { institutional } \\
\text { framework }\end{array}$} & \multicolumn{2}{|l|}{ Resources } & $\begin{array}{l}\text { Estimated by three indicators: funds availability, } \\
\text { assessment of the regulation process, and degree of } \\
\text { public participation in the formulation of specific } \\
\text { water projects }\end{array}$ \\
\hline & & \multicolumn{2}{|l|}{ Projects } & $\begin{array}{l}\text { Assessment of the number, type and potential } \\
\text { impact of the projects under execution in } \\
\text { institutions related to water management in the city }\end{array}$ \\
\hline & & \multicolumn{2}{|l|}{ Personnel } & $\begin{array}{l}\text { Degree of training of water managers, satisfaction } \\
\text { inside water-related institutions, and transparency } \\
\text { in contracting processes. A proxy for social ethics } \\
\text { and knowledge capacity }\end{array}$ \\
\hline \multirow{3}{*}{$\begin{array}{l}\text { Participation } \\
\text { (Personal } \\
\text { aspects) }\end{array}$} & \multirow{3}{*}{$\begin{array}{l}\text { Degree of } \\
\text { involvement of } \\
\text { institutional and } \\
\text { individual actors in } \\
\text { interaction spaces } \\
\text { where public } \\
\text { engagement with } \\
\text { water authorities } \\
\text { becomes possible }\end{array}$} & \multirow{3}{*}{$\begin{array}{l}\text { Interactions } \\
\text { (emergent, } \\
\text { composite } \\
\text { descriptor) }\end{array}$} & Attitudes & $\begin{array}{l}\text { Attitudes as behaviors and other observable } \\
\text { expressions of values and worldviews that might } \\
\text { affect the natural and social environment }\end{array}$ \\
\hline & & & Worldviews & $\begin{array}{l}\text { Worldviews are the temporal and ultimately } \\
\text { normative projections emanating from the other } \\
\text { two indicators within this descriptor }\end{array}$ \\
\hline & & & Values & $\begin{array}{l}\text { Personal values as drivers for more conscious } \\
\text { environmental behavior and more active social } \\
\text { involvement }\end{array}$ \\
\hline
\end{tabular}

Indicators were defined and calculated using a combination of adapted methods [72,80,81]. They were primarily selected in terms of their relevance to assess the satisfaction of the descriptors. The final decision of which indicators or variables to use was based on the following criteria: (a) coherence with the conceptual framework; (b) pertinence to assess specific aspects of the governance for sustainability of the system; (c) minimum correlation between parameters at the same level (overlapping is minimized if the conceptual framework is correctly applied); and (d) availability and reliability of local information. When more than one potential parameter at a certain level was 
identified, we either aggregated parameters in a single value (as in the case of indicators used for descriptors within Planning) or selected one of the possible indicators (as in the indicator for Costs, which could have been substituted by a number of other alternative economic indicators).

It is important to note that lack of data is more the rule than the exception when performing complex, transdisciplinary studies such as those required to building sustainability indices. This is not a problem in itself, as these tools are intended to help the process of decision-making by using the best available information in a given time and place. As stated by Gibson ([82], p. 90), "part of the problem [of sustainability assessment] is the inadequacy of our knowledge." The number and type of descriptors and indicators is relatively flexible, as they depend to a great extent on the context. They can also vary according to the composition of the assessment team, the stakeholders involved, or the amount and quality of the information available. However, it is paramount that descriptors and indicators keep pointing to their respective descriptor or aspect. Preliminary assessments can be made with few, simple indicators. We might proceed to more complex assessments if we want to detect and solve subtler problems. That does not mean that the first assessment was inadequate. It was only performed with simpler or fewer indicators.

\section{Results and Discussion}

Table 2 shows the results obtained for the SWGI of the city of Salta, Argentina, which was used as a practical example to illustrate the method. The governance of the entire system obtained 49 points (Table 2, bottom of column 9). This value falls in the Danger (yellow) category. The aspects Access and Planning obtained scores within the Good (green) range, and Participation was considered Unacceptable (red).

At the descriptor level, Costs was considered in the Good range because the amount needed to pay sufficient water consumption per household represents a small proportion $(1.9 \%)$ of the official minimum wage. Information was given a relatively low value, in the Danger zone, as the websites of the three most important institutions of the WSMS in Salta (namely CoSAySa, ENRESP, and SRH) appeared insufficient in terms of function and content after assessing them according to the method described in [83]. Access to relevant information was considered a crucial indicator to assess the sustainability of this system but, to date, none of the most significant water-related institutions have created a user-friendly mechanism to provide quality information on the water and sanitation system. The lack of such a communication channel in a country with high internet penetration was considered detrimental to the sustainability of the system. Water Needs obtained the maximum score; the company has a system by which a minimum drinking water allowance of $10 \mathrm{~m}^{3}$ is subsidized (via a government fund) to those households that demonstrate a combined income below the official poverty line. With an average of 3.8 persons per household in Salta [63], this allowance is equivalent to $87.7 \mathrm{~L} / \mathrm{p}$.d (liters per person per day). According to [76], the average daily water requirement for survival is around $5 \mathrm{~L} / \mathrm{p} . \mathrm{d}$, while a basic water requirement standard for human needs could be established at $50 \mathrm{~L} / \mathrm{p} . \mathrm{d}$ (see extreme values of the transformation function in Table 2). A comprehensive institutional assessment was performed for CoSAySa, ENRESP, and SRH in order to assign values to the descriptors Resources, Projects, and Personnel, within the Planning aspect (see [77] for more details). The descriptor Interactions obtained a very low score owing to the small 
number of participatory events (Audiences) held by the water company during its private and public periods (only two significant public audiences in the last ten years were convened to discuss investments and projects in water management and provision). A more detailed description of the way indicators and specific variables were calculated, and a short explanation of the rationale behind the construction of transformation functions is provided in the Appendix available as digital supplements to this article.

Table 2. The SWGI for the city of Salta, Argentina. Aggregated indicators were built with more than one variable, as indicated in Table 1 . Indicator values were converted to a standardized scale by means of semiquantitative transformation functions (TF) where 0 and 100 are the lowest and highest possible values of governance for sustainability for a specific category. $\mathrm{L} / \mathrm{p} . \mathrm{d}=$ liters of drinking water per person per day.

\begin{tabular}{|c|c|c|c|c|c|c|c|c|c|}
\hline 1 & 2 & 3 & 4 & 5 & 6 & 7 & 8 & 9 & 10 \\
\hline \multirow[t]{2}{*}{ Aspect } & \multirow[t]{2}{*}{ Descriptor } & \multirow[t]{2}{*}{ Indicator } & \multirow[t]{2}{*}{ Units } & \multirow[t]{2}{*}{ Value } & \multicolumn{2}{|c|}{ TF } & \multicolumn{3}{|c|}{ Governance for sustainability } \\
\hline & & & & & 0 & 100 & Indicator & Descriptor & Range \\
\hline \multirow[t]{3}{*}{ Access } & Costs & Water Cost & $\%$ & 1.9 & 5 & 0.2 & 64 & 67 & Good \\
\hline & Information & Web Sites & $\%$ & 36.7 & 0 & 100 & 37 & & \\
\hline & Needs & Water Needs & L/p.d & 87.7 & 5 & 50 & 100 & & \\
\hline \multirow[t]{3}{*}{ Planning } & Resources & Aggregated & $\%$ & 69.5 & 0 & 100 & 70 & 58 & Good \\
\hline & Projects & Aggregated & $\%$ & 48.5 & 0 & 100 & 49 & & \\
\hline & Personnel & Aggregated & $\%$ & 57.4 & 0 & 100 & 57 & & \\
\hline \multirow[t]{2}{*}{ Participation } & Interactions & Audiences & Events/year & 0.2 & 0 & 1 & 20 & 20 & Unacceptabl \\
\hline & & & & & & & SWGI = & 49 & Danger \\
\hline
\end{tabular}

Estimated values for variables and indicators were converted to a unified scale by means of linear transformation functions defined by the research team (Table 2, columns 6 and 7). For Web Sites and for the aggregated indicators corresponding to the descriptors Resources, Projects, and Personnel, values were assigned directly in a centesimal scale. Transformation functions can vary depending on the variables selected, the actors involved in the assessment, and the experience of the members comprising the facilitation team. This is not an inconvenience as long as criteria are consistent and explicit for all the participants, especially when comparative assessments need to be made.

Calculation procedures used, assumptions made, and actual figures obtained for this particular case study are not as important as the bottom-line idea we want to convey, namely that some sort of semiquantitative assessment of WSMS is not only possible, but also important if we want to move from rhetoric to action in issues such as governance and sustainability. Failure to provide some sort of quantitative indicators of diagnosis and progress will be faced with skepticism and distrust by engineers and decision-makers alike, especially in those cases where decisions are mostly being made by relatively technocratic institutions such as water companies.

Figure 3 shows results arranged as modified radar diagrams. These "governance for sustainability triangles" can be a visual aid to understanding the complex issues under analysis [71]. They are 
straightforward and give a rapid indication of the degree to which the governance or sustainability of a process or system complies with a specified standard. With a single glance at the largest triangle, we can see that immediate action is needed to raise the level of Participation above the established threshold value of 50, indicated with a thick line. Access and Planning are above the threshold. However, when Access is analyzed in more detail (top left triangle), we see that Information (a descriptor) is deficient. We also immediately appreciate that Water Needs obtained the best possible score. The Planning triangle (top right) shows a more homogeneous behavior, with Projects slightly below the threshold (in the Danger range), Personnel slightly above (in the Good range), and Resources in a comparatively safer zone, although not yet in the Excellent range.

Figure 3. The SWGI for Salta represented as governance for sustainability triangles. Large triangle at the bottom shows the values obtained at the level of aspects. Access and Planning are shown in smaller triangles above. Participation has no triangle as it has been evaluated with only one descriptor (Interactions). The thresholds values (50 points) are indicated in each triangle with a thick, full line.

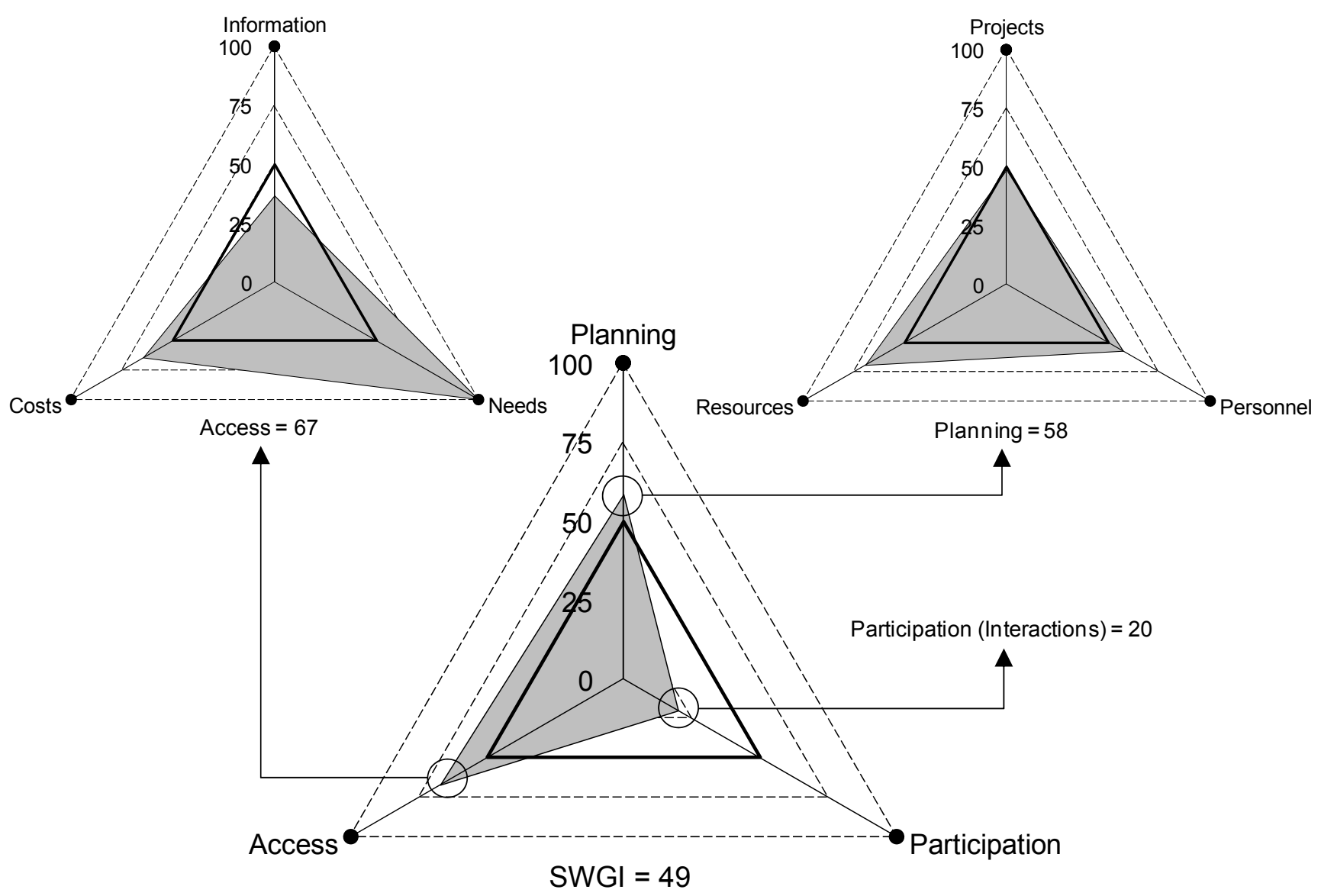

Based on this analysis, we can identify control measures. For example, they might focus on the weakest aspects of the system as the first part of a gradual improvement strategy. Strategies can be established in different ways according to the availability of funds, the requirements of regulatory bodies, and other local constraints and circumstances. They can be based on new acceptability thresholds, specific targets for different levels, or gradual improvement of the index as a whole. Once measures are taken, their effectiveness can be monitored in a process of continuous improvement 
and reassessment [80]. In the medium- or long-term, all aspects, descriptors, and indicators should ideally be above the established threshold values for each particular case, as long as thresholds are considered to be target values. Successful implementation of any improvement strategy also requires commitment and cooperation on the part of companies (such as water utilities) and authorities, vis-àvis the financial, logistic, and administrative obligations involved.

The limitations of any assessment method must also be apparent to all parties. To begin with, the use of sustainability indicators involves a certain degree of circularity, since sustainability is a human vision loaded with human values. Therefore, sustainability indicators are not usually developed through a process of hypothesis setting and testing; instead, they are selected to gauge attainment of the locally agreed, admittedly normative and relatively prescriptive, version of the concept of sustainability (see [60], p. 43). Our index, the SWGI, has been developed to explain the governance aspects of a specific WSMS in a particular location at a given point in time. Whether this or a similar scheme can be applied to other resources, cases, or moments, remains to be seen. On the other hand, even though the aggregation of categories into single numerical values such as indices or indicators is very useful for communication and planning purposes, highly aggregated indicators might hide deficits in some areas of the system under assessment. Subjective estimations are also prone to continuous changes and depend to a great extent on personal experience and knowledge, and on the number and representativeness of the members of the assessment team. Translation of opinions into semiquantitative measures is not without risks, and it must be facilitated by experts for it to be meaningful. This translation can be done by means of convergence participatory techniques or other tools used for environmental and social assessment $[68,79,84]$.

Decision making can be simpler, quicker, and more helpful for solving problems and facilitating societal interactions when quantitative measurements such as indicators are available. Indicators must be founded on solid theoretical and scientific principles and on the other hand, in the field of sustainability, "pure science...must be translated into useful applied models" ([48], p. 409). We know that models, even those built on carefully chosen, openly debated criteria and represented by specific indicators, are rarely meant to be the final word. Instead, while "with few exceptions, sustainability advocates are convinced that setting out a basic working set of explicit general criteria is both possible and valuable," we see that "virtually everyone recognizes that local differences matter and that case specific additions and elaborations are needed" ([82], p. 89). The information provided by indicators should be used with caution. Indicators are simplifications and must not replace reality. In this respect, individual indicators are less important than the collective information provided by a complete, conceptually robust system of indicators [73]. Therefore, a variety of different indicators could be chosen to represent a given descriptor in a particular place. The selection of the "right" indicators for each case requires in-depth knowledge of local settings and consultation with relevant stakeholders [85]. The importance of historical and political contexts should not be underestimated because indicators can never entirely capture the complexities that only a comprehensive context analysis can unveil.

The conceptual framework adopted presupposes that all vertices of any triangle are essential and equally important in governance for sustainability. In some specific cases, however, it could be necessary to assign different weights to the categories. Whatever the case might be, deficiencies at any corner might render the entire system unsustainable. In those cases, actions will always be needed to 
correct detected problems, no matter how healthy other aspects of the system might appear. Overall aggregation can give the entire SWGI a value above the threshold, and this is important for communication purposes, but we should not ignore the information obtained at each level (aspects, descriptors, indicators) to orient decision making and action setting.

The concept of governance for sustainability is paramount for guiding management systems to more desirable situations. It can become a management tool for change towards more sustainable systems and more intergenerational equity. Governance and sustainability, as facilitating concepts, can help societies identify and manage their daily problems while increasing social cohesion and mutual understanding. Governance for sustainability should then contribute to the generation of an adaptive decision-making process that can facilitate societal interactions and problem solving, acknowledging and dealing with power asymmetries and potential conflicts in a constructive way. Should this not be the case, the concepts of governance, sustainability, and governance for sustainability lose most of their usefulness and risk being neglected or even abandoned altogether.

\section{Conclusions}

In this paper, we presented a new approach to studying the complex issues related to the governance and sustainability of water and sanitation management systems (WSMS). We highlighted the relationships between governance and sustainability and combined both concepts into a new conceptual framework we believe can be useful for decision making.

As a practical example, we applied this conceptual framework to analyze the governance of the WSMS of the city of Salta, in northern Argentina. We developed and estimated the Sustainable Water Governance Index (SWGI), a semiquantitative measure that can explain and help improve both the governance and the sustainability of the WSMS under study.

The SWGI for the city of Salta obtained an overall value of 49 on a scale from 0 to 100 . This value falls into the Danger range of our governance for sustainability scale, and indicates that corrective measures are needed. Values obtained for individual indicators show, for example, that the degree of public participation and open access to information were particularly unsatisfactory. On the other hand, water tariffs are relatively affordable, and a government program subsidizes a minimum water allowance that covers basic water needs to those below the poverty line.

We presented and discussed advantages and limitations of the SWGI. Our overall contention is that a semiquantitative index, complemented by a careful analysis of the social, political, and historical context, can help build a decision-making process that is oriented towards the establishment of more sustainable WSMS.

\section{Acknowledgments}

Part of the information contained in this work was kindly provided by the SRH, ENRESP, CoSAySa, and the Institute of Groundwater for Latin America (Instituto de Aguas Subterráneas para Latinoamérica-INASLA) from the National University of Salta (UNSa). All those who participated in meetings and workshops are gratefully acknowledged. This project was financed by CONICET (Project PIP 11420090100392), the Research Council of UNSa (Project 1857), and the National Ministry of Science, Technology and Productive Innovation (MINCyT) (Project PFIP 2008-1). 
Thanks are due to two anonymous reviewers who, by (very) critically but also (very) helpfully commenting on several theoretical and practical aspects of the paper, provided us with enlightening new information and ideas that greatly improved the final version. Remaining mistakes and inaccuracies are entirely our fault. Many thanks to Craig Hutton for his grammatical input.

\section{Conflict of Interest}

The authors declare no conflict of interest.

\section{References}

1. Ostrom, E. A diagnostic approach for going beyond panaceas. PNAS 2007, 104, 15181-15187.

2. Ostrom, E. A general framework for analyzing sustainability of social-ecological systems. Science 2009, 325, 419-422.

3. Bertrand-Krajewski, J.L.; Barraud, S.; Chocat, B. Need for improved methodologies and measurements for sustainable management of urban water systems. Environ. Impact. Assess. Rev. 2000, 20, 323-331.

4. Berger, T.; Birner, R.; Diaz, J.; McCarthy, N.; Wittmer, H. Capturing the complexity of water uses and water users within a multi-agent framework. Water Resour. Manag. 2007, 21, 129-148.

5. Just Sustainabilities. Development in an Unequal World; Agyeman, J., Bullard, R.D., Evans, B., Eds.; MIT Press: Cambridge, USA, 2003.

6. Ballabh, V. Governance of Water: Issues and Challenges. In Governance of Water. Institutional Alternatives and Political Economy; Ballabh, V., Ed.; SAGE Publications: New Delhi, India, 2008; pp. 1-19.

7. Grigg, N. Governance and Management for Sustainable Water Systems; IWA publishing: London, UK, 2011.

8. UNDP (United Nations Development Programme). What Will It Take to Achieve the Millennium Development Goals? An International Assessment; UNDP: New York, USA, 2010.

9. Voß, J.P.; Bauknecht, D.; Kemp, R. Reflexive Governance for Sustainable Development; Edward Elgar: Cheltenham, UK, 2006.

10. Evans, B.; Joas, M.; Sundback, S.; Theobald, K. Governing Sustainable Cities; Earthscan: London, UK, 2005.

11. Kemp, R.; Parto, S.; Gibson, R. Governance for sustainable development: Moving from theory to practice. Int. J. Sustain. Dev. 2005, 8, 12-30.

12. World Bank. Governance and Development; World Bank: Washington, USA, 2007.

13. World Bank. Equity and Development; World Development Report; World Bank: Washington, USA, 2006.

14. Horton, L. Is World Bank "good governance" good for the poor? Central American experiences. Comp. Sociol. 2012, 11, 1-28.

15. Barry, J. Rethinking Green Politics. Nature, Virtue and Progress; Sage Publications: London, UK, 1999.

16. Dobson, A. Environmental citizenship: Towards sustainable development. Sustain. Dev. 2007, $15,276-285$. 
17. Hoppe, R. The Governance of Problems. Puzzling, Powering, Participation; The Policy Press: Bristol, UK, 2010.

18. Moreyra, A. Multiple Territories in Dispute. Water Policies, Participation and Mapuce Indigenous Rights in Patagonia, Argentina. Ph.D. Thesis, Wageningen University, The Netherlands, 3 June 2009.

19. Kooiman, J.; Jentoft, S. Meta-governance: Values, norms and principles, and the making of hard choices. Publ. Admin. 2009, 87, 818-836.

20. Hufty, M. Investigating policy processes: The Governance Analytical Framework (GAF). In Research for Sustainable Development: Foundations, Experiences, and Perspectives; Wiesmann, U., Hurni, H., Eds.; NCCR North-South/Geographica Bernensia: Bern, Switzerland, 2011; pp. 403-424.

21. Hufty, M. La gouvernance est-elle un concept opérationnel? Proposition pour un cadre Analytique. Fédéralisme-Régionalisme 2008, 7, 3150. Available online: http://popups.ulg.ac.be/ federalisme/document.php?id=635 (accessed on 23 March 2012).

22. Mitchell, R.; Agle, B.; Wood, D. Toward a theory of stakeholder identification and salience: Defining the principle of who and what really counts. Acad. Manag. Rev. 1997, 22, 853-886.

23. Etzioni, A. Modern Organizations; Englewood Cliffs: Prentice-Hall, NJ, USA, 1964.

24. Bryant, R.L.; Bailey, S. Third World Political Ecology; Routledge: New York, USA, 1997.

25. Liberation Ecologies. Environment, Development, Social Movements; Peet, R., Watts, M., Eds.; Routledge: London, UK, 1996.

26. Robbins, P. Political Ecology. A Critical Introduction. Critical Introductions to Geography; Blackwell Publishing: Malden, USA, 2004.

27. Meadowcroft, J.; Farrell, K.; Spangenberg, J. Developing a framework for sustainability governance in the European Union. Int. J. Sustain. Dev. 2005, 8, 3-11.

28. WCED (World Commission on Environment and Development). Our Common Future; Oxford University Press: Oxford, UK, 1987.

29. Tijmes, P.; Luijf, R. The sustainability of our common future: an inquiry into the foundations of an ideology. Tech. Soc. 1995, 17, 327-336.

30. Mebratu, D. Sustainability and sustainable development: historical and conceptual review. Environ. Impact Assess. Rev. 1998, 8, 493-520.

31. Seghezzo, L. The five dimensions of sustainability. Environ. Polit. 2009, 18, 539-556.

32. Norgaard, R.B. Sustainability as intergenerational equity: economic theory and environmental planning. Environ. Impact Assess. Rev. 1992, 12, 85-124.

33. Hanley, N. Cost-Benefit Analysis. In Principles of Environmental and Resource Economics. A Guide for Students and Decision-Makers, 2nd ed.; Folmer, H., Gabel, H.L., Eds.; Edward Elgar Publishing: Cheltenham, UK, and Northampton, MA, USA, 2000, pp. 104-129.

34. Spaargaren, G.; Mol, A. Sociology, environment, and modernity: Ecological modernization as a theory of social change. Soc. Nat. Resour. 1992, 5, 323-344.

35. Giljum, S.; Hak, T.; Hinterberger, F.; Kovanda, J. Environmental governance in the European Union: Strategies and instruments for absolute decoupling. Int. J. Sustain. Dev. 2005, 8, 31-46.

36. Fiala, N. Measuring sustainability: Why the ecological footprint is bad economics and bad environmental science. Ecol. Econ. 2008, 67, 519-525. 
37. Arrow, K.; Bolin, B.; Costanza, R.; Dasgupta, P.; Folke, C.; Holling, C.S.; Jansson, B.-O.; Levin, S.; Maler, K.-G.; Perrings, C.; Pimentel, D. Economic growth, carrying capacity, and the environment. Ecol. Appl. 1996, 6, 13-15.

38. Ziegler, R. The politics of operationalisation: Sustainable development and the eco-space approach. Environ. Polit. 2009, 18, 163-181.

39. Bosselmann, K.; Engel, R.; Taylor, P. Governance for Sustainability. Issues, Challenges, Successes; IUCN: Bonn, Germany, 2008.

40. Bosselmann, K. The Principle of Sustainability. Transforming Law and Governance; Ashgate: Hampshire, UK, 2008.

41. Newell, P. The marketization of environmental governance: Manifestations and implications. In The Crisis of Global Environmental Governance: Towards a New Political Economy of Sustainability; Park, J., Conca, K., Finger, M., Eds.; Routledge: London, UK and New York, USA, 2008; pp. 77-95.

42. Escobar, A. Culture sits in places: Reflections on globalism and subaltern strategies of localization. Polit. Geogr. 2001, 20, 139-174.

43. Adam, B. Timescapes of Modernity. The Environmental and Invisible Hazards; Routledge: London, UK and New York, USA, 1998.

44. Šlaus, I.; Jacobs, G. Human capital and sustainability. Sustainability 2011, 3, 97-154.

45. O’Neill, J. Happiness and the good life. Environ. Val. 2008, 17, 201-220.

46. Friends of the Earth and New Economic Foundation. The Happy Planet Index. An Index of Human Well-Being and Environmental Impact; New Economic Foundation: London, UK, 2006.

47. Pfahl, S. Institutional sustainability. Int. J. Sustain. Dev. 2005, 8, 80-96.

48. Norton, B. Sustainability: A Philosophy of Adaptive Ecosystem Management; The University of Chicago Press: Chicago, USA and London, UK, 2005.

49. McShane, K. Anthropocentrism vs. nonanthropocentrism: Why should we care? Environ. Val. 2007, 16, 169-185.

50. Latta, A. Locating democratic politics in ecological citizenship. Environ. Polit. 2007, 16, 377-393.

51. Taylor, B. "Place" as prepolitical grounds of democracy. An Appalachian case study in class conflict, forest politics, and civic networks. Am. Behav. Sci. 2009, 52, 826-845.

52. Enserink, B.; Patel, M.; Kranz, N.; Maestu, J. Cultural factors as co-determinants of participation in river basin management. Ecol. Soc. 2007, 12, 24. Available online: http://www.ecologyand society.org/vol12/iss2/art24/ (accessed on 4 October 2012).

53. Arnstein, S. A ladder of citizen participation. J. Am. Plann. Assoc. 1969, 35, 216-224.

54. Reed, M.; Evely, A.; Cundill, G.; Fazey, I.; Glass, J.; Laing, A.; Newig, J.; Parrish, B.; Prell, C.; Raymod, C.; Stringer, L. What is social learning? Ecol. Soc. 2010, 15, r1. Available online: http://www.ecologyandsociety.org/vol15/iss4/resp1/ (accessed on 14 July 2011).

55. Cooke, B.; Kothari, U. Participation: The New Tyranny?; Zed Books: London, UK and New York, USA, 2001.

56. Barry, J. Sustainability, political judgment and citizenship: Connecting green politics and democracy. In Democracy and Green Political Thought. Sustainability, Rights and Citizenship; Doherty, B., De Geus, M., Eds.; Routledge: London, UK, 1996; pp. 113-130. 
57. Littig, B.; Grießler, E. Social sustainability: A catchword between political pragmatism and social theory. Int. J. Sustain. Dev. 2005, 8, 65-79.

58. Molle, F.; Mollinga, P. Water poverty indicators: Conceptual problems and policy issues. Water Pol. 2003, 5, 529-544.

59. Ness, B.; Urbel-Piirsalu, E.; Anderberg, S.; Olsson, L. Categorising tools for sustainability assessment. Ecol. Econ. 2007, 60, 498-508.

60. Bell, B.; Morse, S. Sustainability Indicators: Measuring the Immeasurable?, 2nd ed.; Earthscan Publications: London, UK, 2008.

61. Spangenberg, J. Sustainable development indicators: Towards integrated systems as a tool for managing and monitoring a complex transition. Int. J. Global Environ. Issues 2009, 9, 318-337.

62. Saleth, R.M.; Dinar, A. The Institutional Economics of Water. A Cross-Country Analysis of Institutions and Performance; Edward Elgar: Cheltenharn, UK, 2004.

63. INDEC (Instituto Nacional de Estadísticas y Censos). Statistical data (in Spanish). Available online: http://www.indec.com.ar (accessed on 26 May 2010).

64. Government of Salta Province. Ley N ${ }^{\circ}$ 7571. Constitución de Sociedad de la Compañia Salteña de Agua y Saneamiento S.A. (CoSAySa) Estatuto Social (Law No. 7571. Formation of CoSAySa and the company bylaws) (in Spanish); Government of Salta Province: Salta, Argentina, 2009.

65. Azpiazu, D. La mercantilización del agua en Argentina (Mercantilization of water in Argentina) (in Spanish). Remesas y Desarrollo 2008, 58, 41-55.

66. Araral, E. Reform of water institutions: Review of evidences and international experiences. Water Pol. 2010, 12, 8-22.

67. Iribarnegaray, M.A.; Copa, F.R.; Gatto D’Andrea, M.L.; Arredondo, M.F.; Cabral, J.D.; Correa, J.J.; Liberal, V.I.; Seghezzo, L. A comprehensive index to assess the sustainability of water and sanitation management systems. J. Water Sanitat. Hyg. Dev. 2012, 2, 205-222.

68. Linstone, H.; Turoff, M. The Delphi Method: Techniques and Applications; Institute of Technology: New Jersey, USA, 1995. Available from: http://is.njit.edu/pubs/delphibook/ (accessed on 23 March 2012).

69. Belton, V. A comparison of the analytic hierarchy process and a simple multi-attribute value function. Eur. J. Oper. Res. 1986, 26, 7-21.

70. Torquebiau, E. Are tropical agroforestry home gardens sustainable? Agr. Ecosyst. Environ. 1992, 41, 189-207.

71. Bossel, H. Indicators for Sustainable Development: Theory, Method, Applications. A Report to the Balaton Group; International Institute for Sustainable Development (IISD): Winnipeg, Canada, 1999.

72. Hellström, D.; Hjerpe, M.; Van Moeffaert, D. Indicators to Assess Ecological Sustainability in the Urban Water Sector; Clamers University of Technology: Götheborg, Sweden, 2004.

73. Spangenberg, J.; Pfahl, S.; Deller, K. Towards indicators for institutional sustainability: Lessons from an analysis of Agenda 21. Ecol. Indicat. 2002, 2, 61-77.

74. Cahill, A. The human right to water-A right of unique status: The legal status and normative content of the right to water. Int. J. Hum. Right. 2005, 9, 389-410. 
75. Bohoslavsky, J.; Justo, J. Protección del Derecho Humano al Agua y Arbitrajes de Inversión (Protection of the Human Right to Water and Investment Conflicts) (in Spanish); Colección Documentos de Proyectos; CEPAL: Santiago, Chile, 2011.

76. Gleick, P. Basic water requirements for human activities: Meeting basic needs. Water Int. 1996, $21,83-92$.

77. Iribarnegaray, M.; Copa, F.; Ruiz, C.; Sauad, J.; Liberal, V.; Seghezzo, L. Aspectos institucionales para la evaluación de la sustentabilidad de la gestión del agua y el saneamiento en la provincia de Salta (Institutional aspects for the assessment of the sustainability of water and sanitation management in the province of Salta) (in Spanish). Avances en Energías Renovables $y$ Medio Ambiente 2010, 14, 103-109.

78. Social Discourse and Environmental Policy: An Application of Q Methodology; Addams, H., Proops, J., Eds.; Edward Elgar: Northampton, MA, USA, 2000.

79. Vugteveen, P.; Lenders, R.; Devilee, J.; Van der Veeren, R.; Wiering, M.; Hendriks, J. Stakeholder value orientations in water management. Soc. Nat. Resour. 2010, 23, 1-17.

80. Bell, B.; Morse, S. Measuring Sustainability. Learning from Doing; Earthscan Publications: London, UK, 2006.

81. OECD (Organization for Economic Co-operation and Development). Guidance on Sustainability Impact Assessment; OECD: Paris, France, 2010.

82. Gibson, R.B. Sustainability Assessment. Criteria and Processes; Earthscan Publications: London, UK, and Stirling, VA, USA, 2005.

83. Codina, L. Evaluación de recursos digitales en línea: Conceptos, indicadores y métodos (Assessment of digital resources on line: concepts, indicators and methods) (in Spanish). Revista Española de Documentación Científica 2000, 23, 9-44.

84. Dinar, A.; Saleth, R.M. Can water institutions be cured? A water institutions health index. Water Sci. Tech. Water Supply 2005, 5, 17-40.

85. López Ridaura, S. Multi-Scale Sustainability Evaluation. A Framework for the Derivation and Quantification of Indicators for Natural Resource Management Systems. Ph.D. Thesis, Wageningen University, The Netherlands, 16 September 2005.

(C) 2012 by the authors; licensee MDPI, Basel, Switzerland. This article is an open access article distributed under the terms and conditions of the Creative Commons Attribution license (http://creativecommons.org/licenses/by/3.0/). 